\title{
THE CZECH REPUBLIC AND SLOVAKIA IN TERMS OF MORTALITY FROM MALIGNANT NEOPLASMS: SIMILAR OR OPPOSITE TENDENCIES?
}

\author{
Klára Hulíková Tesárková \\ Department of Demography and Geodemography, Faculty of Science, Charles University, Prague, Czech Republic
}

\begin{abstract}
SUMMARY
In Europe, a steady mortality decline has been observed from the 1950s, however, Central and Eastern Europe underwent a period of stagnation or even worsening from the 1960s to 1980s. Since that time an evident mortality decline could be observed in that part of Europe too. Within the post-communist countries, mortality development has been most favourable in Slovenia, the Czech Republic and Slovakia. The aim of this study is to describe the latest development of cancer mortality in two selected countries - the Czech Republic and Slovakia. These two countries have much in common, including many similar long term trends in demographic or social indicators' development. The study evaluates whether cancer mortality development differs in the two countries or rather follows a similar trend. From the presented results it is clear that the development apparently differs namely according to sex. The results according to selected particular causes of death (from the group of malignant neoplasms) are presented as well. It could be assumed that many aspects could be improved by prevention programmes or screening.
\end{abstract}

Key words: cancer, mortality, Czech Republic, Slovakia, sex, decomposition

Address for correspondence: K. Huliková Tesárková, Department of Demography and Geodemography, Faculty of Science, Charles University, Albertov 6, 128 43, Prague 2, Czech Republic. E-mail: klara.hulikova@natur.cuni.cz

https://doi.org/10.21101/cejph.a4360

\section{INTRODUCTION}

Mortality development in many Central or Eastern European countries during the second half of the 20th century may be divided into 3 specific periods. The first one is the period of rapid improvement in the 1950s followed by the second period of stagnation or even worsening from the 1960s to 1980s, and the last one is a period of improvement from the 1990s in Central Europe and a period of several mortality crises in the Eastern post-communist countries. For this study only two countries were selected for a deeper analysis - the Czech Republic and Slovakia. Both countries have much in common, including a shared history as two parts of one country until 1993 . Also their general mortality development in the 20th century was similar. When life expectancy at birth (below referred to as "life expectancy" without any specification of age) is used as a description of the mortality level in both countries, it can be seen that its value increased by almost 10 years during the 1950s. Although the life expectancy of both males and females was higher in the Czech Republic at the beginning of the 1950s, at the end of that decade values in both countries were almost the same (around 73 years for females and 68 for males). The following period was also typical in both countries with only a slight increase for females and a stagnation (or worsening in the 1960s) for males. From 1990, mortality development in both countries started to differ. In the Czech Republic, the life expectancy of females started to increase more rapidly and in Slovakia a mild rate of increase was observed. In case of males, however, life expectancy had already started to increase in the Czech Republic during the 1980s while in Slovakia its value only started to grow after 1990 (Fig. 1).

Favourable mortality development in most developed countries could also be connected with changes in the structure of deaths according to different causes $(1,2)$. In accordance with the theory of cardiovascular revolution (3), the proportion of cardiovascular diseases among all deaths has decreased in the most developed countries, the proportion of this group of causes compared to total deaths decreased from about $50 \%$ (in the 1950 s) to nearly $30 \%$ at the end of the first decade of the 21 st century (4). The situation is not yet the same in the two analysed countries. In 2013 in both countries, around $43 \%$ of males died because of cardiovascular

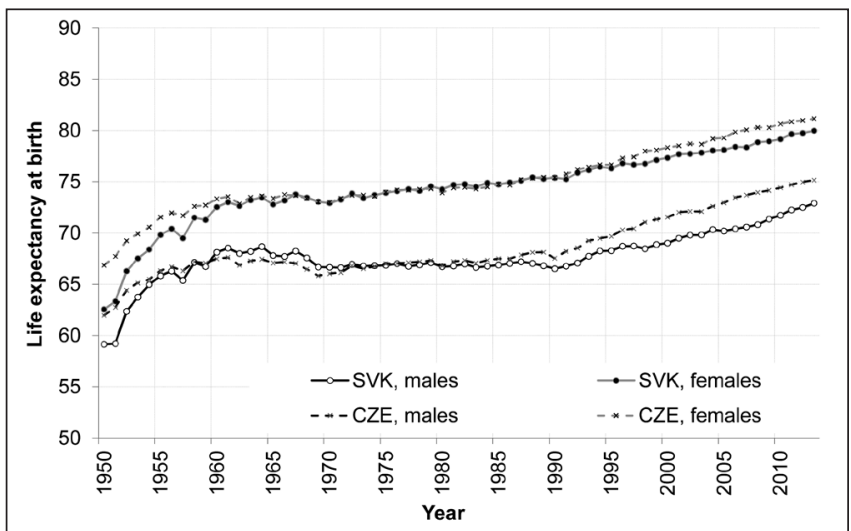

Fig. 1. Life expectancy at birth, males, females, Czech Republic, Slovakia, 1950-2013. 
diseases and around $28 \%$ because of malignant neoplasms. For females the proportion of cardiovascular diseases remains even higher in comparison to males (almost 52\% in the Czech Republic and more than $57 \%$ in Slovakia). However, the proportion of malignant neoplasms is nearly identical (slightly above $22 \%$ in both countries). The increase in this proportion has been more rapid in Slovakia.

In both countries mortality from cardiovascular diseases has decreased rapidly during the studied period. Also, both countries show the most rapid decrease in cancer mortality when compared to other post-communist countries (5). However, because of differing development in the number of deaths from malignant neoplasms as a proportion of all deaths in both studied countries (Table 1), there is a need for a more in-depth study of cancer mortality.

The aim of this study is to describe the latest development of cancer mortality in the Czech Republic and Slovakia and to find out whether cancer mortality development differs in the two countries or rather follows a similar trend. Any differences will be studied in more detail using data on particular causes of death or an analytical method of decomposition showing the overall trends in mortality according to selected causes of deaths from the class of malignant neoplasms.

\section{MATERIALS AND METHODS}

Just for a basic comparison of life expectancy at birth, data from the Human Mortality Database, University of California, Berkeley, USA, and Max Planck Institute for Demographic Research, Germany, was used. For detailed analysis, data on deaths according to age groups and groups of causes of death were used as well as population size within the same age structure in the middle of the year (exposure). Cause specific analysis was applied only to the years 1994 and later because since then the 10th revision of International Classification of Diseases (ICD) has been used in both studied countries, so no data transformations had to be used.

Numbers of deaths according to causes of death, were taken from the Czech Statistical Office (numbers of deaths according to a detailed list of causes of death; numbers were aggregated into the same structure of causes as the data for Slovakia) and the Statistical Office of the Slovak Republic (numbers of deaths according to causes of death). For the Czech Republic data were available in the same structure from 1994 to 2013, for Slovakia data were available in the same structure only from 1996 to 2013. So as it was possible to compare the whole period from the years 1994 to 2013, numbers of deaths according to age groups and causes and exposure for years 1994 and 1995 in Slovakia were extracted from the WHO Mortality Database using the VBA program for data extraction from the WHO Mortality Database (6).

For simple description of cancer mortality standardised mortality rates were used. In the calculation the age-specific mortality rates were weighted by the new European standard (7). The more detailed analysis was performed using the method of decomposition. This method produces the age and cause-specific contributions to the difference in life expectancy between the two analysed populations. In this way the differences in life expectancy between 1994 and 2013 for both countries were decomposed. This method of decomposition was proposed by Pollard (8) and is calculated as follows:

$$
e_{0}^{B}-e_{0}^{A}=\sum_{i, x}\left[\left(m_{x}^{(i) A}-m_{x}^{(i) B}\right) * w_{x} * n\right]
$$

where $m_{x}^{(i) A}$ is the age specific mortality rate in age group $<x ; x+n)(n$ is the width of the age interval) in population $\mathrm{A}$ from a cause (or group of causes) of death $i . w_{x}$ are the age-specific weights:

$$
w_{x}=\frac{1}{2} *\left[\left(\frac{l_{x}^{B}+l_{x+1}^{B}}{2 * l_{0}} * \frac{e_{x}^{B}+e_{x+1}^{B}}{2}\right)+\left(\frac{l_{x}^{A}+l_{x+1}^{A}}{2 * l_{0}} * \frac{e_{x}^{A}+e_{x+1}^{A}}{2}\right)\right]
$$

where $l_{x}^{A}$ is the number of survivors to age group $\left.<x ; x+n\right)$ in population A from the life table and $e_{x}^{A}$ is the life expectancy at age $x$ in the same life table. In both lite tables the $l_{0}$ is the same value of the root of the table. For the first age group the weight is calculated differently - with higher weight of age $x(0.92)$ and lower weight of age $x+1(0.08)$. This reflects the higher concentration of deaths during the first year of life just after birth.

\begin{tabular}{|c|c|c|c|c|c|c|c|c|}
\hline & \multicolumn{8}{|c|}{ Czech Republic } \\
\hline & \multicolumn{4}{|c|}{ Males } & \multicolumn{4}{|c|}{ Females } \\
\hline & 1991 & 1994 & 2004 & 2013 & 1991 & 1994 & 2004 & 2013 \\
\hline Malignant neoplasms & 24.8 & 26.6 & 29.9 & 27.3 & 20.4 & 21.2 & 24.4 & 22.3 \\
\hline Cardiovascular diseases & 51.7 & 50.9 & 46.0 & 43.0 & 60.3 & 60.1 & 56.8 & 51.8 \\
\hline \multirow[t]{4}{*}{ Other } & 23.6 & 22.6 & 24.1 & 29.7 & 19.3 & 18.7 & 18.7 & 25.9 \\
\hline & \multicolumn{8}{|c|}{ Slovakia } \\
\hline & \multicolumn{4}{|c|}{ Males } & \multicolumn{4}{|c|}{ Females } \\
\hline & 1991 & 1994 & 2004 & 2013 & 1991 & 1994 & 2004 & 2013 \\
\hline Malignant neoplasms & 21.1 & 22.8 & 24.8 & 28.4 & 16.7 & 18.3 & 19.6 & 22.0 \\
\hline Cardiovascular diseases & 48.2 & 49.2 & 47.9 & 43.6 & 58.5 & 60.3 & 61.3 & 57.4 \\
\hline Other & 30.7 & 27.9 & 27.4 & 28.0 & 24.8 & 21.4 & 19.0 & 20.6 \\
\hline
\end{tabular}

Table 1. Proportion (\%) of selected groups of causes of death among all deaths, males, females, 1991, 1994, 2004, 2013

Source: Czech Statistical Office (http://www.czso.cz/csu/2014edicniplan.nsf/p/130067-14), Slovak POPIN (http://www.infostat.sk/slovakpopin/) 
Table 2. Age-standardised mortality rates from selected causes, males, females, Czech Republic, Slovakia, 1994, 2013 (per 1,000)

\begin{tabular}{|l|c|c|c|c|c|c|c|c|}
\hline \multirow{2}{*}{ Cause of death } & \multicolumn{4}{|c|}{ Slovakia } & \multicolumn{2}{c}{ Cemales } & \multicolumn{2}{c|}{ Males } \\
\cline { 2 - 9 } & \multicolumn{2}{|c|}{ Males } & \multicolumn{2}{c|}{ Czech Republic } & \multicolumn{2}{c|}{ Females } \\
\cline { 2 - 10 } & 1994 & 2013 & 1994 & 2013 & 1994 & 2013 & 1994 & 2013 \\
\hline C00-C14 & 0.2970 & 0.2834 & 0.0309 & 0.0352 & 0.1406 & 0.1179 & 0.0256 & 0.0279 \\
\hline C15 & 0.1205 & 0.1218 & 0.0177 & 0.0134 & 0.0984 & 0.0949 & 0.0143 & 0.0170 \\
\hline C16 & 0.3990 & 0.2821 & 0.1982 & 0.1074 & 0.4387 & 0.1727 & 0.1990 & 0.0795 \\
\hline C18 & 0.2953 & 0.4512 & 0.1623 & 0.2085 & 0.4908 & 0.3286 & 0.2694 & 0.1722 \\
\hline C19-C21 & 0.3941 & 0.3985 & 0.1689 & 0.1407 & 0.4168 & 0.2351 & 0.1849 & 0.1024 \\
\hline C22 & 0.1379 & 0.1503 & 0.0876 & 0.0556 & 0.1730 & 0.1345 & 0.0872 & 0.0569 \\
\hline C25 & 0.1930 & 0.2039 & 0.1094 & 0.1376 & 0.2499 & 0.2518 & 0.1707 & 0.1802 \\
\hline C32-C34 & 1.4172 & 1.0548 & 0.1673 & 0.2185 & 1.4977 & 0.9531 & 0.2467 & 0.3091 \\
\hline C43 & 0.0421 & 0.0790 & 0.0374 & 0.0417 & 0.0632 & 0.0589 & 0.0363 & 0.0250 \\
\hline C50 & 0.0111 & 0.0065 & 0.3547 & 0.3972 & 0.0081 & 0.0051 & 0.4577 & 0.3139 \\
\hline C53 & - & - & 0.0950 & 0.0901 & - & - & 0.0936 & 0.0683 \\
\hline C54-C55 & - & - & 0.1386 & 0.0963 & - & - & 0.1197 & 0.0826 \\
\hline C56 & - & - & 0.1051 & 0.1069 & - & - & 0.1578 & 0.1316 \\
\hline C61 & 0.3883 & 0.5066 & - & - & 0.5345 & 0.4526 & - & - \\
\hline C64 & 0.1149 & 0.1573 & 0.0550 & 0.0573 & 0.2460 & 0.1658 & 0.1167 & 0.0723 \\
\hline C67 & 0.1874 & 0.1992 & 0.0203 & 0.0385 & 0.1912 & 0.1636 & 0.0452 & 0.0435 \\
\hline C81-C96 & 0.2220 & 0.3022 & 0.1504 & 0.1660 & 0.3020 & 0.2669 & 0.1887 & 0.1589 \\
\hline
\end{tabular}

Source: Czech Statistical Office, 2015; Statistical Office of the Slovak Republic, 2015; WHO, 2015; author's calculation

C00-C14 - MN of lip; C15 - MN of oesophagus; C16 - MN of stomach; C18 - MN of colon; C19-C21 - MN of rectosigmoid junction, rectum, anus and anal canal; C22 - MN of liver and intrahepatic bile ducts; C25 - MN of pancreas; C32-C34 - MN of larynx, trachea, bronchus and lung; C43 - malignant melanoma of skin; C50 - MN of breast; C53 - MN of cervix uteri; C54-C55 - MN of corpus uteri, uterus and other unspecified parts of uterus; C56 - MN of ovary; C61 - MN of prostate; C64 - MN of kidney, except renal pelvis; C67 - MN of bladder; C81-C96 - malignant neoplasms, stated or presumed to be primary, of lymphoid, haematopoietic and related tissue

For the detailed analysis of cancer mortality, 17 causes of deaths (groups of causes) were selected; all of them representing causes from the group of malignant neoplasms (Table 2 and 3).

\section{RESULTS}

In accordance with expectations, the overall mortality development is positive in both analysed countries. Using the age-standardised mortality rate for a basic comparison, one can follow the decreasing trend for both sexes in both countries over the whole studied period. For males, the differences between the two countries has been visible from the middle of the 1990s, for females only from the middle of the 2000s. Only in the latest years, the decline in mortality in Slovakia has been more rapid (Fig. 2). The trend would be similar, or even more visible, if the age-standardised mortality rates were calculated only for circulatory diseases (not shown here). However, the picture is completely different when following mortality only from the causes in Chapter II of ICD-10 (Neoplasms). At the beginning of the studied period, the situation was more favourable for both sexes in Slovakia than in the Czech Republic. However, for males the age-standardised cancer mortality rates are nearly the same from 1998, but the decreasing trend is more rapid for Czech males, particularly from the beginning of the 21 st century. During the last years of the studied period, mortality from neoplasms almost levels off in Slovakia. For females, there are not so many fluctuations around the trend. Mortality from neoplasms was lower for Slovak females until the year 2013, where the values of the age-standardised mortality rates for females in both countries were nearly the same. Again the decreasing trend is more rapid in the Czech Republic than in Slovakia, where mortality from neoplasms remains almost unchanged during the studied period (Fig. 3).

Considering the cause-specific mortality rates for Slovak males in 1994 the most common causes of death within malignant neoplasms $(\mathrm{MN})$ were malignant neoplasm of larynx, trachea, bronchus and lung (C32-C34), followed by malignant neoplasm of stomach (C16) and malignant neoplasm of rectosigmoid junction, rectum, anus, and anal canal (C19-C21). Mortality from the first two causes decreased up until the year 2013 by about a quarter. Mortality from the third cause even increased slightly. As a result the most common cause of death within malignant neoplasms for Slovak males in 2013 was still MN of lung. However, the second most frequent malignant neoplasm in 2013 was malignant neoplasm of prostate (C61), where the age-standardised mortality rate increased from 1994 by about $30 \%$. The third most frequent cause of death within malignant neoplasms in 2013 was malignant neoplasm of colon (C18), where the mortality rate increased by more than 50\% from 1994. For males in the Czech Republic in 1994, the most frequent causes of death within malignant neoplasms were the same as in Slovakia in 2013, i.e. MN of lung, prostate and colon. However, mortality from all these causes of death decreased by $15 \%$ (MN of prostate) to $33 \%$ (MN of colon) 
Table 3. Ratios of age-standardised mortality rates from selected causes between the years 1994 and 2013, males, females, Czech Republic, Slovakia

\begin{tabular}{|l|c|c|c|c|}
\hline \multirow{2}{*}{ Cause of death } & \multicolumn{2}{|c|}{ Slovakia } & \multicolumn{2}{c|}{ Czech Republic } \\
\cline { 2 - 5 } & Males & Females & Males & 1.09 \\
\hline C00-C14 & 0.95 & 1.14 & 0.84 & 1.18 \\
\hline C15 & 1.01 & 0.75 & 0.39 & 0.40 \\
\hline C16 & 0.71 & 0.54 & 0.67 & 0.64 \\
\hline C18 & 1.53 & 1.29 & 0.56 & 0.55 \\
\hline C19-C21 & 1.01 & 0.83 & 0.78 & 0.65 \\
\hline C22 & 1.09 & 0.64 & 1.01 & 1.06 \\
\hline C25 & 1.06 & 1.26 & 0.64 & 1.25 \\
\hline C32-C34 & 0.74 & 1.31 & 0.93 & 0.69 \\
\hline C43 & 1.88 & 1.11 & 0.62 & 0.69 \\
\hline C50 & 0.59 & 1.12 & - & 0.73 \\
\hline C53 & - & 0.95 & - & 0.69 \\
\hline C54-C55 & - & 0.70 & - & 0.83 \\
\hline C56 & - & 1.02 & 0.85 & - \\
\hline C61 & 1.30 & - & 0.67 & 0.62 \\
\hline C64 & 1.37 & 1.04 & 0.86 & 0.96 \\
\hline C67 & 1.06 & 1.90 & & 0.84 \\
\hline C81-C96 & 1.36 & 1.10 & & \\
\hline
\end{tabular}

Source: Czech Statistical Office, 2015; Statistical Office of the Slovak Republic, 2015; WHO, 2015; author's calculation

C00-C14 - MN of lip; C15 - MN of oesophagus; C16 - MN of stomach; C18 - MN of colon; C19-C21 - MN of rectosigmoid junction, rectum, anus and anal canal; C22 - MN of liver and intrahepatic bile ducts; C25 - MN of pancreas; C32-C34 - MN of larynx, trachea, bronchus and lung; C43 - malignant melanoma of skin; C50 - MN of breast; C53 - MN of cervix uteri; C54-C55 - MN of corpus uteri, uterus and other unspecified parts of uterus; C56 - MN of ovary; C61 - MN of prostate; C64 - MN of kidney, except renal pelvis; C67 - MN of bladder; C81-C96 - malignant neoplasms, stated or presumed to be primary, of lymphoid, haematopoietic and related tissue

and 36\% (MN of lung) until 2013. Despite this decrease, the same three causes (or groups of causes) remained the most frequent in 2013 in Czech males (Table 2).

For females the development was completely different. In 1994, for Slovak females the most common cause of death within malignant neoplasms was malignant neoplasm of breast (C50), followed by MN of stomach (C16) and MN of rectum (C19-C21).
Whereas mortality from MN of stomach decreased by 2013 by nearly $46 \%$ and from $\mathrm{MN}$ of rectum by more than $16 \%$, mortality from $\mathrm{MN}$ of breast increased by about $12 \%$. These trends resulted in the fact, that $\mathrm{MN}$ of breast still remained the most frequent cause of death within malignant neoplasms for Slovak females in 2013. However, in 2013 this cause was followed by MN of lung, where the mortality rate increased from 1994 by more than $30 \%$, and by

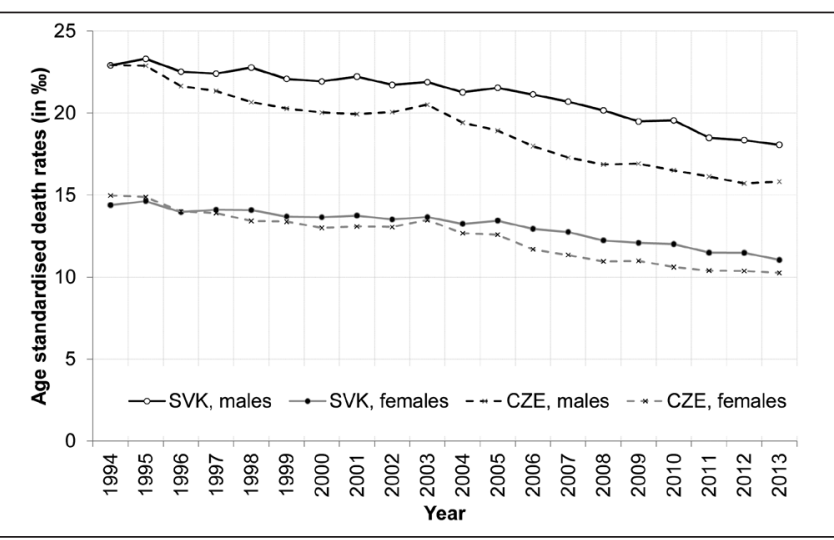

Fig. 2. Age-standardised mortality rate, males, females, Czech Republic, Slovakia, 1994-2013 (per 1,000).

Source: Czech Statistical Office, 2015; Statistical Office of the Slovak Republic, 2015; WHO, 2015; author's calculation

SVK - Slovakia, CZE - Czech Republic, age-specific mortality rates are weighted using the European standard (7)

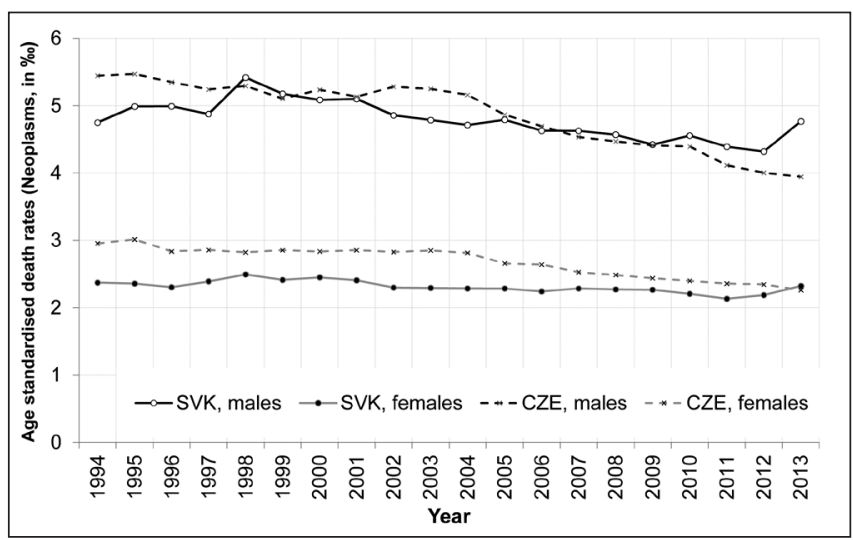

Fig. 3. Age-standardised mortality rate from Neoplasms (ICD10, dg. C00-D48), males, females, Czech Republic, Slovakia, 1994-2013 (per 1,000).

Source: Czech Statistical Office, 2015; Statistical Office of the Slovak Republic, 2015; WHO, 2015; author's calculation

SVK - Slovakia, CZE - Czech Republic, age-specific mortality rates are weighted using the European standard (7) 
MN of colon where mortality rates in 2013 were more than 28\% higher in comparison to 1994. Also in the Czech Republic MN of breast was the most common cause of death from malignant neoplasms for females in 1994. However, mortality from this cause decreased up until 2013 by more than 31\%. In 1994, this cause was followed by $\mathrm{MN}$ of colon, for which the mortality rate decreased until 2013 by $36 \%$. The third most frequent cause of death within the studied group of causes was $\mathrm{MN}$ of lung in Czech females in 1994. By 2013, mortality from this cause had increased, making it the second most frequent cause of death for Czech females within malignant neoplasms. The most frequent cause remained $\mathrm{MN}$ of breast, however, the mortality rates for these two causes of death were nearly the same. The third most common cause within the studied group of causes in 2013 was malignant neoplasm of pancreas (C25). The mortality rate from this cause remained nearly the same in 2013 as in 1994 (Table 2).

As described above, the most common cancers in the Czech and Slovak Republics in 1994 and 2013 partially differ - this is caused not only by sex specificity in causes of death (e.g. MN of breast) but also by different trends in mortality developments over time (between 1994 and 2013). The mortality development from malignant neoplasms (measured by the change in age-standardised mortality rates) was the most favourable in case of Czech males (among both sexes in both compared countries). The only cause of death where the age-standardised mortality rate increased between 1994 and 2013 for Czech males was for MN of pancreas, the rate increased by less than $1 \%$. The mortality development in Czech females was nearly as favourable - mortality rates for

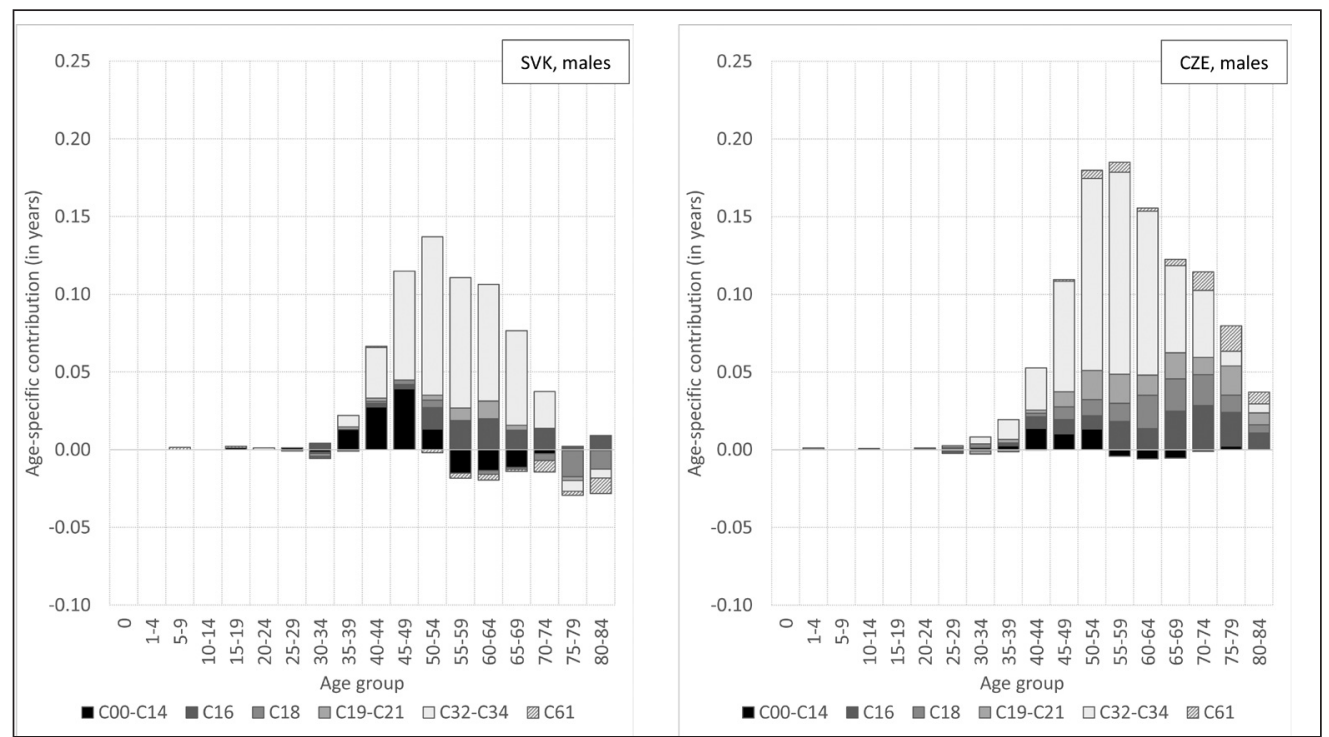

Fig. 4. Age-specific contributions of selected causes of death to the increase in life expectancy between 1994 and 2013 , males, Slovakia (left), Czech Republic (right).

Source: Czech Statistical Office, 2015; Statistical Office of the Slovak Republic, 2015; WHO, 2015; author's calculation C00-C14 - MN of lip; C16 - MN of stomach; C18 - MN of colon; C19-C21 - MN of rectum ; C32-C34 - MN of lung; C61 - MN of prostate

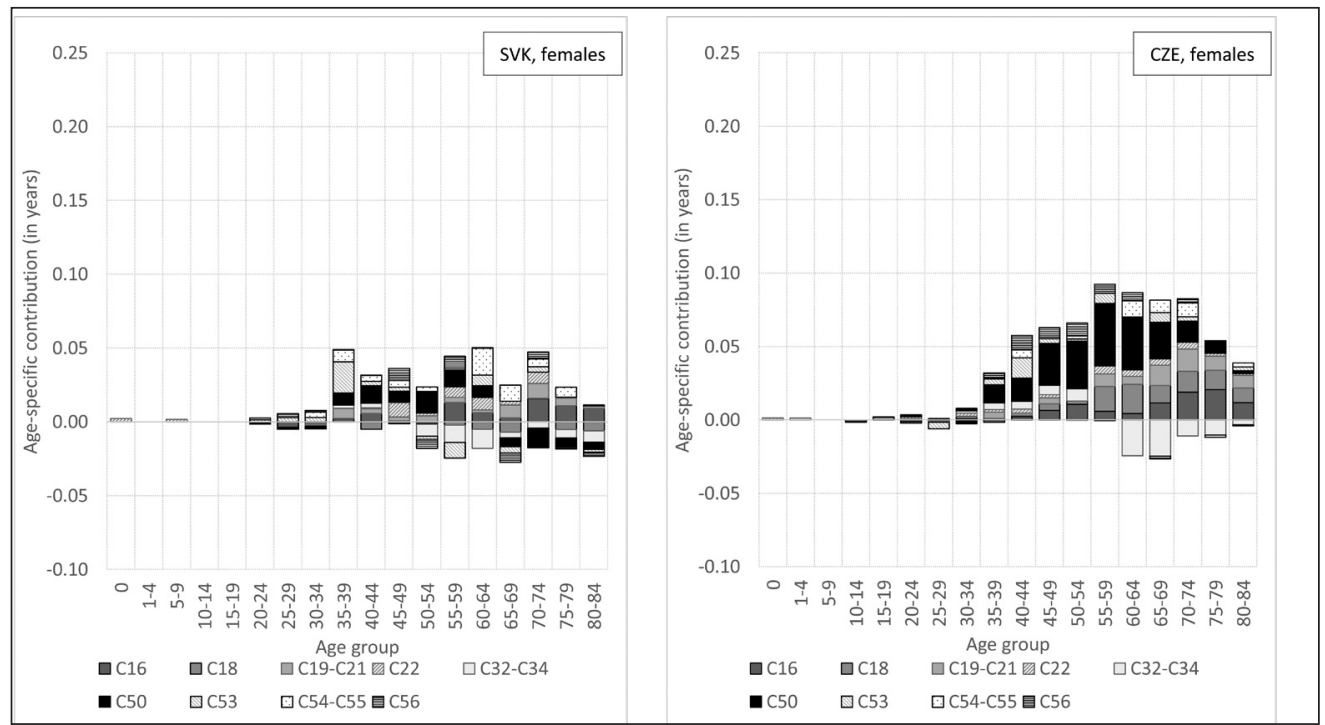

Fig. 5. Age-specific contributions of selected causes of death to the increase in life expectancy between 1994 and 2013 , females, Slovakia (left), Czech Republic (right).

Source: Czech Statistical Office, 2015; Statistical Office of the Slovak Republic, 2015; WHO, 2015; author's calculation

C16 - MN of stomach; C18 - MN of colon; C19-C21 - MN rectum; C22 - MN of liver and intrahepatic bile ducts; C32-C34 - MN of lung; C50 - MN of breast; C53 - MN of cervix uteri; C54-C55 - MN of corpus uteri, uterus and other unspecified parts of uterus; C56 - MN of ovary 
almost all malignant neoplasms decreased between 1994 and 2013. There was only a slight increase in case of $\mathrm{MN}$ of pancreas and $\mathrm{MN}$ of lip, oral cavity and pharynx (C00-C14) - by about $5 \%$ and nearly $9 \%$, respectively. However, there are two exceptions from this favourable development - malignant neoplasm of oesophagus (C15) and above all $\mathrm{MN}$ of lung. For these two causes of death the mortality rates increased by more than $18 \%$ and $25 \%$, respectively (Table 3 ).

On the other hand, the mortality development for both Slovak males and females is much less favourable. For males it is possible to find only four causes of death from the studied list, where the mortality rate decreased between 1994 and 2013 - the highest decrease could be observed for $\mathrm{MN}$ of lung and $\mathrm{MN}$ of stomach, where mortality rates decreased by more than $25 \%$ and nearly $30 \%$, respectively. For all the other causes the mortality rates increased. The situation among Slovak females was similarmortality rates decreased for only five causes of deaths, the most significant decrease can be seen in case of $\mathrm{MN}$ of stomach, by almost $46 \%$, malignant neoplasm of liver and intrahepatic bile ducts (C22), and malignant neoplasm of corpus uteri, uterus and other unspecified parts of uterus (C54-C55). For these causes mortality rates decreased by $36 \%$ and $30 \%$, respectively (Table 3 ).

As shown above, life expectancy at birth in both countries is increasing, however, the increase is evidently higher in the Czech Republic than in Slovakia. Clearly the question arises what is the reason for different trend in developments of cancer mortality in the countries ultimately reflected by different trends in life expectancy noted between 1994 and 2013? This question can be easily answered using any decomposition method. In this study, the decomposition proposed by Pollard (8) was used. This method can quantitatively present the contributions of changes in mortality from selected causes (or groups of causes) according to age (or age groups) to the difference in life expectancy between the two compared populations. The decomposition was calculated separately for males and females as well as for both countries. Positive values of calculated contributions represent positive effect on the life expectancy (i.e. a contribution to its increase), negative values represent rather a contribution to the decrease of life expectancy between compared years. The sum of all contributions for all causes of death and across all age groups is the total difference in life expectancy. The most important advantage of this method is that the contributions to the change of life expectancy reflect not only the total change in mortality from selected causes of deaths, but also their importance among other causes of death. Moreover, it is possible to see at what ages the positive or negative contributions are concentrated. So that the results remain clear and readable, contributions of only 6 causes or groups of causes are depicted in the graphs for males and 9 causes for females.

As can be seen from the graph, for Slovak males the most important contributor to the increase in life expectancy from the group of cancers is $\mathrm{MN}$ of lung. Life expectancy increased, above all, thanks to the positive development of mortality from this cause in the middle and higher age groups, above 40 to around 70 years (Figure 4 ). As mentioned previously, mortality from this cause decreased during the studied period by about $25 \%$. The contributions of $\mathrm{MN}$ of stomach are concentrated particularly at higher ages (50 to about 75 years). Moreover, there are positive contributions from $\mathrm{MN}$ of lip, but only in the lower ages (from 35 to about 50 years). On the other hand, at higher ages mortality from this group of causes contributed rather negatively to the overall change in life expectancy. There are also negative contributions from MN of prostate (Fig. 4), these are concentrated predominantly at higher ages (about 70 years and over).

As mentioned above, there is only one cause of death from the analysed list of causes for males in the Czech Republic where the age-standardised mortality rate increased over the studied period. However, MN of lip mortality also slightly increased in some age groups and so contributed negatively to the change in life expectancy (Fig. 4). But this negative contribution is concentrated only at ages from 55 to 70 years and those negative contributions are very small and accompanied by higher positive contributions at lower ages. Also in case of Czech males, the most important contributor to the increase in life expectancy between 1994 and 2013 was $\mathrm{MN}$ of lung. The contributions from this cause are concentrated predominantly in age groups from 45 to 75 . In comparison to the situation in Slovakia, MN of prostate contributed to the increase of life expectancy for Czech males. The contributions from this cause are greatest at the highest ages but they are already visible from around 45 years of age.

For males, it could be summed up that cancer mortality development was almost similar in the Czech Republic and Slovakia with only a few differences: the first one is the fact that cancer mortality decreased more in the Czech Republic, so the contributions to the increase in life expectancy are higher in comparison to Slovakia (in the Czech Republic the decrease in cancer mortality added 1.05 years to the increase in life expectancy while in Slovakia the overall contribution of cancer mortality was only 0.56 years). Secondly, in the Czech Republic mortality from almost all analysed causes of death decreased. In Slovakia, it is possible to find causes where mortality increased during the studied period (MN of prostate particularly at the highest ages and $\mathrm{MN}$ of colon in the middle age groups, from around 50 to 75 years). For both countries, the highest contribution to the increase in life expectancy is due to the decrease in mortality from $\mathrm{MN}$ of lung (contribution of 0.59 years in the Czech Republic and of 0.44 years in Slovakia).

As might be expected, the situation is more complicated for females in both countries. In case of Slovak females the sum of all contributions to the change in life expectancy from all analysed causes is rather small ( 0.20 years), because the positive contributions are almost completely offset by the negative ones. Moreover, the contributions are often not systematic across age. In Figure 5 , there are negative contributions visible particularly from $\mathrm{MN}$ of lung, concentrated at ages 50 and over. An irregular development is visible in case of specific female causes - MN of breast, cervix uteri or ovary. For these causes the mortality development is favourable (and contributions to life expectancy are positive) at some ages and unfavourable (negative) at other ages. Above all, in case of $\mathrm{MN}$ of breast a clear mortality improvement is visible at lower ages (from around 35 to 65 years), and a negative one at higher ages (above 65). This straight difference of development before and after the age of 65 could be analysed and discussed in more detail in future research, as the reasons may lie in many aspects including preventive programmes.

Although for females in the Czech Republic the contributions of analysed causes of death ( 0.58 years) are lower in comparison to males, in comparison to Slovak females their contributions 
to the changes in life expectancy are rather positive. The most significant positive contributions are visible for $\mathrm{MN}$ of breast in all age groups (except for a very small decrease at 30-34 years). Also, contributions of other analysed causes of death are rather systematic across age groups. Most of the contributions are concentrated at around 55 to 75 years of age. However, at these ages the positive contributions are accompanied by negative values from $\mathrm{MN}$ of lung. As stated above, the overall age-specific mortality rate from this group of causes increased for Czech females by more than $30 \%$ between 1994 and 2013 . The Czech female population is negatively affected by mortality from this cause at ages above 60 years. At lower ages mortality from this cause slightly decreased (Fig. 5). This should be analysed more in detail with the aim of finding possible reasons for the development (e.g. smoking habits of females during the second half of the 20th century or environmental factors).

When we try to summarize the results for Czech and Slovak females, the cancer mortality development of females is not as favourable as for males. Above all, in case of Slovak females, the positive contributions to the change in life expectancy (caused by decrease in cancer mortality) are almost completely offset by the negative ones. In both countries females suffer from the obvious increase in mortality from MN of lung. In the Czech Republic, the overall age-standardised mortality rate from this cause increased by more than $25 \%$, in Slovakia by more than $30 \%$. However, whilst in the Czech Republic this cause negatively affected those above 60, in Slovakia this effect was seen after 50 years of age. At lower ages the mortality development from this cause is rather positive, particularly in Czech females. Female specific causes (MN of breast, cervix uteri or ovary) also differ in both analysed countries. Whereas in the Czech Republic mortality from these causes decreased during the studied period in all analysed age groups (with only small exceptions), in Slovakia the development across age is rather irregular, or the positive development occurred only at lower ages (below 65 years) and is accompanied by negative development at higher ages. All these facts should be studied in future research.

\section{DISCUSSION AND CONCLUSION}

As described above, both studied countries have much in common, including a shared history and general mortality development. The Czech Republic and Slovakia have been going through a period of general mortality improvement since 1990 . However, evident differences can be found between the two countries with regard to mortality development. The main positive trend in mortality is influenced above all by improvements in cardiovascular mortality since in both countries cardiovascular diseases still remain the main cause of death for both sexes. The positive development of cardiovascular mortality is supposedly driven, above all, by a reduction in major cardiovascular risk factors (primary prevention) and technological development in medicine and surgery $(9,10)$. However, with regard to the second main group of causes of death, neoplasms, different tendencies were revealed. For males, the trend is rather positive in both countries, though in the Czech Republic a more rapid mortality decrease is observable. Nearly the same holds for females, but in case of Slovakia there are such contradictory tendencies according to particular causes of death that the overall trend of cancer mortality could be perceived rather as unchanged. Females in the Czech Republic as well as in Slovakia suffer from increasing mortality rates in MN of lung. Moreover, in Slovakia especially at higher ages, the problem of increasing mortality from female-specific causes (such as MN of breast, cervix uteri or ovary) remains. Finding any clear reasons for this development would hardly be possible without more in-depth research of the important aspects described in other types of studies. One of the most important could be the efficiency of screening and preventive programmes in both countries (11).

According to the research (5), in the Czech Republic and Slovakia, there are populations with rapid mortality decline. This also holds for some causes of death from malignant neoplasms. However, cancer mortality still remains relatively high in those countries. On the other hand, the Czech Republic and Slovakia are not the only countries in Central Europe where mortality from malignant neoplasms remains high or has decreased only slowly during recent years. Hungary is often mentioned as an example where cardiovascular mortality decreased while mortality from malignant neoplasms showed no significant change (12). Also, in countries of Western, Northern and Southern parts of Europe mortality development during the second half of the 20th century was impacted, above all, by changes in cardiovascular mortality. In these countries cancer mortality remained nearly stable during the period and its proportion among all causes of death increased (4). The reasons for this development were found, above all, to be better and more affordable medical treatment and possibilities of prevention with respect to cardiovascular diseases in comparison to malignant neoplasms.

As shown in this study, for females in the Czech Republic and Slovakia, an upcoming problem seems to lie in the rising mortality from MN of lung. These causes of death could be assumed as closely related to smoking habits (13). Smoking-attributable diseases can be found among cardiovascular diseases as well as among malignant neoplasms (4). It is supposed that the peak of mortality from smoking-attributable cardiovascular diseases occurred during the 1970s in Western Europe and from smokingattributable cancer diseases about one decade later (4). However, as consequence of different smoking habits for males and females during the 20th century, the peak for females could be expected later. Stabilization of smoking-attributable cancer mortality in Western Europe has been seen only in recent years (4). Based on the results presented above, we can expect a future decrease in smoking-attributable cancer mortality for females during the next decade or two in Central European countries. Even now the mortality is decreasing in lower age groups. There are also other relevant factors which should be studied in relation to lung cancer mortality. For example, the prevalence may be tied to the socioeconomic status of the population, although this relationship was not confirmed for females (14).

When searching for reasons which could explain the differences between the Czech Republic and Slovakia, it should be mentioned that there are even bigger differences within the group of post-communist countries in Central and Eastern Europe. Possible reasons could be found in their different social or economic development over the last decades (15). It is also possible to distinguish between countries from this region, which were regarded as being more "western" or "eastern" countries even before 
World War II $(16,17)$. From this perspective the rapid positive development of the Czech Republic could be understood as once again approaching the standards of Western European countries. However, this does not explain fully the differences between the Czech and Slovak part of a former united country. Moreover, it could be proved (18) that according to overall mortality development almost no convergence tendencies between the Czech Republic and Western European countries can be found. However, it should be pointed out, that the cited convergence analysis was not based on cause-specific data.

The development of female-specific cancer mortality, particularly in Slovakia, should be discussed in relation to prevention, because many deaths from these causes could be prevented by screening programmes or detection of malignant neoplasms in the early stages. However, even in other EU countries the coverage of screening programmes is not as high as it should be. According to estimates for cervical cancer screening, only about one third of women of the corresponding age participate $(11,19)$. In dealing with cervical cancer, the incidence rate in the Czech Republic is still relatively high despite the provision of free annual preventive gynaecological examinations. The coverage is estimated to be about one third of females at ages 25-65, but it is expected to be much lower at higher ages (around 17\% of females at ages 60 and over). Moreover, vaccination against HPV infection (which could lead to $\mathrm{MN}$ of cervix uteri) for young girls is financially supported by health insurance companies (20). In Slovakia, the screening programmes are organised similarly, however, written invitations are planned only for the future (20).

As for preventive programmes, many issues could be discussed in relation to the development of cancer incidence or mortality. These discussions are, however, beyond the scope of this study.

\section{Acknowledgement}

This article was written with the support of the Czech Science Foundation as part of work on project no. P404/12/0883 'Cohort life tables for the Czech Republic: data, biometric functions, and trends'.

\section{Conflict of Interests}

None declared

\section{REFERENCES}

1. Omran AR. The epidemiologic transition: a theory of the epidemiology of population change. Milbank Q. 2005;83(4):731-57.

2. Olshansky SJ, Ault AB. The fourth stage of the epidemiologic transition: the age of delayed degenerative diseases. Milbank Q. 1986;64(3):355-91.

3. Vallin J, Meslé F. Convergences and divergences in mortality. A new approach to health transition. Demogr Res [Internet]. 2004 [cited 2014 Mar
1];Spec. Col. 2(Art. 2):11-44. Available from: http://www.demographicresearch.org/special/2/2/s2-2.pdf.

4. Bongaarts J. Trends in causes of death in low-mortality countries: implications for mortality projections. Popul Dev Rev. 2014 Jun; 40(2):189-212.

5. Vrdoljak E, Wojtukiewicz MZ, Pienkowski T, Bodoky G, Berzinec P, Finek J, et al. Cancer epidemiology in Central and South Eastern European countries. Croat Med J. 2011 Aug 15;52(4):478-87.

6. Andreev EM. A VBA program for data extraction from the WHO Mortality Database [Internet]. Rostock: Max Planck Institute for Demographic Research; 2010 [cited 2015 Mar 3]. Available from: http://www.demogr. mpg.de/papers/technicalreports/tr-2010-004.pdf.

7. Eurostat. Revision of the European standard population: report of Eurostat's task force [Internet]. Luxembourg: Publications Office of the European Union; 2013 [cited 2014 Mar 15]. Available from: http:// ec.europa.eu/eurostat/documents/3859598/5926869/KS-RA-13-028-EN. PDF/e713fa79-1add-44e8-b23d-5e8fa09b3f8f.

8. Pollard JH. The expectation of life and its relationship to mortality. J Inst Actuar. 1982;109(2):225-40.

9. Rychtaříková J. The case of the Czech Republic. Determinants of the recent favourable turnover in mortality. Demogr Res [Internet]. 2004 [cited 2014 Mar 1];Spec. Col. 2(Art. 5):105-37. Available from: http:// www.demographic-research.org/special/2/5/s2-5.pdf.

10. Bruthans J, Cífková R, Lánská V, O'Flaherty M, Critchley JA, Holub $\mathrm{J}$, et al. Explaining the decline in coronary heart disease mortality in the Czech Republic between 1985 and 2007. Eur J Prev Cardiol. 2014 Jul;21(7):829-39.

11. Sadovsky O. Cervical cancer screening in Slovakia. Onkológia (Bratisl.). 2014;9(3):144-8. (In Slovak.)

12. Balogh S, Papp R, Jozan P, Csaszar A. Continued improvement of cardiovascular mortality in Hungary - impact of increased cardio-metabolic prescriptions. BMC Public Health. 2010 Jul; 10:422. doi: 10.1186/14712458-10-422.

13. Peto R, Lopez AD, Boreham J, Thun M, Heath C Jr, Doll R. Mortality from smoking worldwide. Br Med Bull. 1996;52(1):12-21.

14. Hrubá F, Fabiánová E, Bencko V, Cassidy A, Lissowska J, Mates D, et al. Socioeconomic indicators and risk of lung cancer in Central and Eastern Europe. Cent Eur J Public Health. 2009;17(3):115-21.

15. Grigoriev P, Shkolnikov V, Andreev E, Jasilionis D, Jdanov D, Meslé F, et al. Mortality in Belarus, Lithuania, and Russia: Divergence in recent trends and possible explanations. Eur J Popul. 2010;26(3):245-74.

16. Coleman DA. Populations of the industrial world - a convergent demographic community? Int J Popul Geogr. 2002;8(5):319-44.

17. Pleško I. Current global and local knowledge and problems of epidemiology of malignant tumors. Onkológia (Bratisl.). 2006;1(1):8-13. (In Slovak.)

18. Hulíková Tesárková K, Kašpar D, Zimmermann P. Convergent and divergent trends in the European mortality: what is the position of Czechia? Geografie. 2015;120(1):26-49. (In Czech.)

19. Ronco G, Anttila A. Cervical cancer screening in Europe - changes over the last 9 years. Eur J Cancer. 2009 Oct;45(15):2629-31.

20. Anttila A, Ronco G, Working group on the registration and monitoring of cervical cancer screening programmes in the European Union; within the European Network for information on cancer (EUNICE). Description of the national situation of cervical cancer screening in the member states of the European Union. Eur J Cancer. 2009 Oct;45(15):2685-708.

Received March 28, 2015 Accepted in revised form July 31, 2017 